Original Article

\title{
NOVEL UMBELLIFERONE PHYTOSOMES: DEVELOPMENT AND OPTIMIZATION USING EXPERIMENTAL DESIGN APPROACH AND EVALUATION OF PHOTO-PROTECTIVE AND ANTIOXIDANT ACTIVITY
}

\author{
PARUL A. ITTADWAR ${ }^{*}$, PRASHANT K. PURANIK ${ }^{2}$ \\ 1,2Department of Pharmaceutical Sciences, Rashtrasant Tukadoji Maharaj Nagpur University, Mahatma Jyotiba Fuley Shaikshanik Parisar, \\ Nagpur 440033 (MS), India \\ Email: parulittadwar06@gmail.com
}

Received: 11 Aug 2016 Revised and Accepted: 23 Nov 2016

\begin{abstract}
Objective: The objective of this study was to develop a novel formulation (Phytosome) of umbelliferone with phospholipid for improved permeability, solubility and hence better pharmacological action.

Methods: The phytosomal complex was prepared by using solvent evaporation method and optimised by applying the Box-Behnken design on the basis of complexation rate and partition coefficient. The formation of phytosomes was confirmed by FTIR, DSC, SEM, XRD, HPTLC and NMR by comparing the results of the complex with the drug. The photoprotective potential of complex against UV-exposure was evaluated in rats and compared with the drug by incorporating it in a gel and estimating the antioxidant enzymes in skin namely reduced glutathione, superoxide dismutase, lipid peroxidation and catalase.

Results: The crystalline drug was completely converted to amorphous complex. The complex showed a good practical yield, drug content and particle size was in the range. The solubility of the complex was determined by partition coefficient method and was found to be better than the drug. The ex vivo and in-vitro permeation of the complex showed improved permeation for complex than the drug. The in vitro antioxidant activity of complex was evaluated by DPPH and ferrozine antioxidant assay and was better than the drug. The photoprotective action of the complex was found to be better than drug on the basis of the content of antioxidant enzymes estimated in the skin.
\end{abstract}

Conclusion: The phytosomal complex was found to show better solubility in the water phase and oil phase, better permeation, better antioxidant activity and a better photo-protective activity when compared to umbelliferone.

Keywords: Umbelliferone phytosome, Solvent evaporation, Box-Behnken design, Partition coefficient, Solubility, Antioxidant activity, Photoprotective activity.

(c) 2017 The Authors. Published by Innovare Academic Sciences Pvt Ltd. This is an open access article under the CC BY license (http://creativecommons.org/licenses/by/4. 0/) DOI: http://dx.doi.org/10.22159/ijpps.2017v9i1.14635

\section{INTRODUCTION}

Phytochemical and phytopharmacological studies have been established for the compositions, therapeutics and overall health boosting capacities of various plants. But phytoconstituents have a disadvantage that they are limited in their effectiveness because they are poorly absorbed and their limited solubility both in water and in lipophilic phases, as well as hydrolytical instability at physiological $\mathrm{pH}$ values, makes them very poorly absorbed both orally and topically [1]. They cannot easily get absorbed and their passage through the lipoidal biological membrane is limited [2]. Many approaches have been developed to improve the bioavailability of these phytoconstituents, such as the inclusion of solubility and bioavailability enhancers, structural modification and entrapment with the lipophilic carriers [3].

Bioavailability can be improved by using novel drug delivery systems [4]. Among these, Phytosome process has been applied successfully to several popular herbal extracts. Phytosomes are phospholipid complexes of the herbal active drug constituent mainly formulated to improve the overall solubility and bioavailability in comparison to the plain herbal drug. They are ideally suited to optimise drug delivery and reduce toxicity [5]. It has been applied to flavonoids, polyphenols, terpenoids, tannins, catechins, etc. for example turmeric, ginseng, hawthorn, etc [6]. Phytosomes results from the reaction of a stoichiometric amount of the phospholipid (phosphatidylcholine) with the standardised extract in a non-polar solvent. Phytosome technology has been considered to be a major advancement in clinical research for active phytoconstituents with poor bioavailability [7].

The Phytosome technology, a novel drug delivery system, produces a little cell, better able to transit from a hydrophilic environment into the lipid-friendly environment of the enterocyte cell membrane and from there into the cell [8]. The hydrophilic moiety (choline group) binds with water soluble phytoconstituents and forms the body while the lipid soluble phosphatidyl moiety forms the tail and envelops the choline bound material. As a result, a lipid compatible molecular complex is formed [9].

Coumarin is a plant flavonoid distributed widely in nature. Substituted coumarin derivatives were reported to have a variety of biological activities. Umbelliferone is yellowish-white in color and crystalline in nature. It absorbs ultraviolet light strongly at several wavelengths and acts as photoactive agent. Umbelliferone has antioxidant properties and can scavenge free radicals generated in the skin as a result of UV exposure when applied topically. Umbelliferone is found to occur in many plants from Apiaceae family such as carrot, coriander and garden angelica, and also in other families, such as bigleaf hydrangea (Hydrangea macrophylla, Hydrangeaceae) or the mouse-ear hawkweed (Hieracium pilosella, Asteraceae). It can be isolated from the fruit of Aegle marmelos [10]. Umbelliferone has a polar hydroxyl group which has the affinity to bind with the phospholipid. Umbelliferone-phosphatidylcholine (UMB-HSPC) complex may be formed due to the interaction between the polar hydroxyl group of umbelliferone and polar choline group of phosphatidylcholine.

As umbelliferone has the desired properties, the present study aims to increase the solubility, permeability, antioxidant activity and the potent photoprotective effect by formulating it as a phospholipid complex.

\section{MATERIALS AND METHODS}

\section{Materials}

Umbelliferone was purchased from Sigma-Aldrich. Inc. (USA) having purity $99 \%$. Phospholipon $90 \mathrm{H}$ was obtained as a gratis sample from 
Lipoid (Germany). All the other chemicals and reagents were of the analytical grade.

\section{Methods}

\section{Preformulation studies}

The presence of umbelliferone was studied by specific identification test by taking $0.5 \mathrm{~g}$ of moistened methanolic drug in a test tube. Filter paper treated with $1 \mathrm{~N}$ sodium hydroxide solution was used to cover the mouth of the tube. Then it was placed in boiling water for a few minutes, and the filter paper was removed and subjected to examination under UV light for fluorescence $[11,12]$. Melting point was determined using Thiele tube method [13].

The analytical method development was done using UV spectroscopic analysis. Calibration of umbelliferone was performed in methanol, ultrapure water and phosphate buffer saline $\mathrm{pH} 7.4$ (PBS). A standard stock solution of $1000 \mu \mathrm{g} / \mathrm{ml}$ was prepared, and from this, a $10 \mu \mathrm{g} / \mathrm{ml}$ solution was prepared and used to determine the $\lambda_{\max }$ and calibration curves were obtained [10].

Characterization of umbelliferone was done by obtaining FT-IR spectra using Shimadzu-IRAFFINITY-1 FT-IR spectrophotometer. The thermal behaviour of the drug was evaluated using differential scanning calorimeter and the enthalpy and melting point range was determined [14]. The various validation parameters like linearity, interday precision, intraday precision, robustness, ruggedness, limit of detection, limit of quantitation and \% recovery/accuracy study were determined in accordance with the ICH guidelines [15].

\section{Preparation of umbelliferone-phospholipid complex}

Accurately weighed amounts of umbelliferone and phospholipon $90 \mathrm{H}$ in stoichiometric molar ratios $(1: 1 / 1: 2 / 1: 3)$ were dissolved in $20 \mathrm{ml}$ dichloromethane and refluxed using condenser at constant temperature $\left(40 / 50 / 60^{\circ} \mathrm{C}\right)$ for a defined period of time $(1 / 2 / 3 \mathrm{~h})$. The mixture was concentrated to $2-3 \mathrm{ml}$ by evaporating the solvent. Complexes were retrieved by precipitation by adding an excess amount of $\mathrm{n}$-hexane. The mixture was then allowed to stand and the residue was dried in a desiccator containing anhydrous calcium chloride [16].

\section{Design of experiments-Box-Behnken design}

The optimisation was carried out using 3 factors, 3 levels BoxBehnken design. Independent variables were the umbelliferonephospholipid ratio $\left(\mathrm{X}_{1}\right)$, process temperature $\left(\mathrm{X}_{2}\right)$ and reaction time $\left(\mathrm{X}_{3}\right)$ for two dependent variables i.e. complexation rate $\left(\mathrm{Y}_{1}\right)$ and partition coefficient $\left(\mathrm{Y}_{2}\right)$ as shown in table 1 . A total of 15 batches were prepared and evaluated for complexation rate and partition coefficient. This data was statistically analysed and validated by Design Expert ${ }^{\circledR}$ (Version 8.0.0, Stat-Ease Inc., Minneapolis, MN) using ANOVA and polynomial equations to find an optimised set of process parameters. The optimised batch was selected using desirability functions. Various 3-D response surface graphs and contour plots were studied. A matrix design was constructed to generate a non-linear quadratic model equation as-

$$
Y=b_{0}+b_{1} X_{1}+b_{2} X_{2}+b_{3} X_{3}+b_{12} X_{1} X_{2}+b_{13} X_{1} X_{3}+b_{23} X_{2} X_{3}+b_{11} X_{1}^{2}+b_{22} X_{2}{ }^{2}+b_{33} X_{3}^{2}
$$

Where $\mathrm{Y}$ is the measured response for each factor level combination; $b_{0}$ is an intercept; $b_{1}$ to $b_{33}$ are regression coefficients fig. $d$ from the observed experimental values of $\mathrm{Y}$; and $\mathrm{X}_{1}, \mathrm{X}_{2}$ and $\mathrm{X}_{3}$ are coded levels of independent variables [16].

Table 1: Dependent and independent variables in Box-Behnken design used for optimisation

\begin{tabular}{|c|c|c|c|c|}
\hline \multirow{2}{*}{ Types of variable } & \multirow{2}{*}{ Variable } & \multicolumn{3}{|c|}{ Optimisation levels used } \\
\hline & & Low (-1) & Medium (0) & High (1) \\
\hline \multirow[t]{3}{*}{ Independent } & $\mathrm{X}_{1}$ (Umbelliferone: Phospholipon) & $1: 1$ & $1: 2$ & $1: 3$ \\
\hline & $\mathrm{X}_{2}$ (Temperature) & $40^{\circ} \mathrm{C}$ & $50^{\circ} \mathrm{C}$ & $60^{\circ} \mathrm{C}$ \\
\hline & $\mathrm{X}_{3}$ (Time) & $1 \mathrm{~h}$ & $2 \mathrm{~h}$ & $3 \mathrm{~h}$ \\
\hline \multirow[t]{2}{*}{ Dependent } & $\mathrm{Y}_{1}$ (Complexation rate) & Maximize & & \\
\hline & $\mathrm{Y}_{2}$ (Partition coefficient) & Minimize & & \\
\hline
\end{tabular}

\section{Characterization of the complex}

\section{Complexation rate of complex}

The amount of complex equivalent to $10 \mathrm{mg}$ of umbelliferone, was dispersed in $5 \mathrm{ml}$ of chloroform. Both the complex and phospholipid were dissolved easily in chloroform, but free umbelliferone remained practically insoluble in chloroform. The non-complexed umbelliferone was separated, dissolved in methanol and assayed using a UVSpectrophotometer (V-630 Jasco 2000 series, Japan) at $324 \mathrm{~nm}$. The free drug concentration was calculated from standard curves. The complexation rate of umbelliferone was determined by the formula:

Complexation rate $(\%)=\left(\mathrm{m}_{2} / \mathrm{m}_{1}\right) \times 100=\left[\left(\mathrm{m}_{1}-\mathrm{m}_{3}\right) / \mathrm{m}_{1}\right] \times 100$

Where $m_{1}$ is the total content of umbelliferone added, $m_{2}$ is the content of umbelliferone present as a complex and $m_{3}$ is free umbelliferone [17].

\section{Determination of solubility by partition coefficient method}

Complex equivalent to $10 \mathrm{mg}$ of umbelliferone was taken in a beaker. To this $10 \mathrm{ml}$ distilled water was added and stirred for $20 \mathrm{~min}$ on a magnetic stirrer. In a $60 \mathrm{ml}$ separating funnel, $10 \mathrm{ml}$ of n-octanol was added, and dispersion of complex in water was added to the funnel. The funnel was uniformly agitated for a period of $2 \mathrm{~h}$ and then kept aside for $30 \mathrm{~min}$. When two distinct layers were formed, they were separated and the solution was diluted and assayed using UV spectrophotometer (V-630 Jasco 2000 series, Japan) by recording absorbance in triplicate. Similar procedure was used for the plain drug. Concentration in both the phases was calculated using calibration equation and partition coefficient was calculated by-

$$
\text { Partition coefficient }=\mathrm{C}_{\mathrm{o}} / \mathrm{C}_{\mathrm{w}}
$$

Where $\mathrm{C}_{0}$-concentration in oil phase, $\mathrm{C}_{\mathrm{w}}$-concentration in water phase [17]

\section{Percentage practical yield}

The percentage practical yield was determined by first calculating the theoretical yield of optimised batch and then weighing the batch to get the practical yield $[16,17]$. The $\%$ practical yield was calculated using the formula-

$\%$ Practical yield $=($ Practical yield $/$ Theoretical yield $) \times 100$

\section{Drug content}

Complex equivalent to $10 \mathrm{mg}$ of umbelliferone $(101.15 \mathrm{mg}$ ) was dissolved in $10 \mathrm{ml}$ methanol to form a solution of concentration approximately $1000 \mu \mathrm{g} / \mathrm{ml}$. From this $100 \mu \mathrm{g} / \mathrm{ml}$ solution was prepared. Then again $0.2 \mathrm{ml}$ was taken using a micropipette and volume was made to $10 \mathrm{ml}$ with methanol to obtain $2 \mu \mathrm{g} / \mathrm{ml}$ and it was evaluated in UV spectrophotometer at $324 \mathrm{~nm}$.

The blank was made by dissolving $10 \mathrm{mg}$ of phospholipid in $10 \mathrm{ml}$ of methanol to form a solution of $1000 \mu \mathrm{g} / \mathrm{ml}$. From this $100 \mu \mathrm{g} / \mathrm{ml}$ solution was prepared and then subsequently $2 \mu \mathrm{g} / \mathrm{ml}$ solution by dilutions. This solution was used as blank. The drug content was calculated for the optimised batch [18].

\section{In vitro antioxidant activity}

\section{DPPH (2, 2-diphenyl-1-picryl hydrazyl) antioxidant assay-}

Preparation of $0.2 \mathrm{mmol}$ DPPH solution-Accurately weighed $7.9 \mathrm{mg}$ of DPPH was dissolved in methanol and volume was made to 1000 $\mathrm{ml}$ to get a $0.2 \mathrm{mmol}$ solution.

Procedure for assay-For the assay $1 \mathrm{ml}$ of each concentration of drug and complex was mixed with $2 \mathrm{ml}$ of $0.2 \mathrm{mmol}$ DPPH solution and 
was evaluated using UV spectrophotometer at $517 \mathrm{~nm}$ and the \% DPPH antioxidant activity was calculated and compared for the complex and drug. The DPPH solution was used as the control and $\%$ DPPH activity was calculated using following formula [19-22]-

$\%$ DPPH radical scavenging activity $=\left[\left(A_{c}-A_{t}\right) / A_{c}\right] \times 100$

\section{$\mathrm{A}_{\mathrm{c}}$-Absorbance of control}

$\mathrm{A}_{\mathrm{t}}-$ Absorbance of test sample

\section{Ferrozine antioxidant assay-}

Preparation of $2 \mathrm{mmol}$ ferrozine solution-Accurately weighed $24.7 \mathrm{mg}$ of ferrozine was dissolved in water and volume was made to $25 \mathrm{ml}$ with distilled water to obtain a solution of $2 \mathrm{Mm}$ concentration. Preparation of $250 \mathrm{mmol}$ ferric chloride solution-Accurately $2483.8 \mathrm{mg}$ of ferric chloride was weighed and dissolved in water and volume was made up to $50 \mathrm{ml}$ with distilled water to get a solution of $250 \mathrm{mmol}$. Procedure for assay-From each solution of drug and complex, $0.25 \mathrm{ml}$ was withdrawn. To it $1.75 \mathrm{ml}$ of methanol, $0.25 \mathrm{ml}$ of $2 \mathrm{mmol}$ ferrozine solution and $0.25 \mathrm{ml}$ of $250 \mathrm{mmol}$ ferric chloride solution were added. The solutions were kept in the dark for $10 \mathrm{~min}$ and their absorbance was noted at $562 \mathrm{~nm}$ against the blank solution. For control, $2 \mathrm{ml}$ of water was taken as blank and a mixture of $1 \mathrm{ml}$ each of ferric chloride solution and ferrozine solution were taken as sample and the absorbance was noted at $562 \mathrm{~nm}$. The \% ferrozine antioxidant activity was calculated as follows [23]-

$\%$ Ferrozine antioxidant activity $=\left[\left(\mathrm{A}_{\mathrm{c}}-\mathrm{A}_{\mathrm{t}}\right) / \mathrm{A}_{\mathrm{c}}\right] \times 100$

\section{High-performance thin layer chromatography (HPTLC)}

A $10 \mu \mathrm{l}$ volume of the standard solution of umbelliferone and complex was applied using $100 \mu \mathrm{l}$ Hamilton syringe in triplicate to an HPTLC plate $(20 \times 10 \mathrm{~cm}, 0.2 \mathrm{~mm}$ thick pre-coated using silica gel $60 \mathrm{~F}_{254}$ ). The plates were developed in a solvent system of toluenemethanol $(9.5: 0.5 \mathrm{v} / \mathrm{v})$ at $25 \pm 2{ }^{\circ} \mathrm{C}$ temperature and $40 \%$ relative humidity until a distance of $8 \mathrm{~cm}$ was achieved. After development, the plates were dried and scanned at $331 \mathrm{~nm}$ for umbelliferone using Camag TLC scanner 3. The peak areas were found and $R_{f}$ values were recorded and compared for the plain drug and complex using WINCATS software [24, 25].

\section{Particle size and zeta potential}

For measurement of the particle size of phytosomal lipid complex, the sample (5 mg) was dispersed in $10 \mathrm{ml}$ deionized water and the mean diameter, polydispersity index and zeta potential was determined using a Delsa Nano Zetasizer, Beckman coulter (Government college of pharmacy, Aurangabad) [17].

\section{Differential scanning calorimetry (DSC)}

DSC curves of umbelliferone, phospholipid, and the complex were recorded using a Differential Scanning Calorimeter, STAR SW 10.00 Mettler (R. C. Patel institute of pharmaceutical education and research, Shirpur). The thermal behaviour was studied by heating $2.0 \pm 0.2 \mathrm{mg}$ of each sample in a covered sample pan under nitrogen gas flow. The analysis was carried out over the temperature range $0-300{ }^{\circ} \mathrm{C}$ at a rate of $10{ }^{\circ} \mathrm{C} \mathrm{min}-1$ and the results were compared for drug and complex $[17,26]$.

\section{FT-IR spectroscopy}

The interaction of umbelliferone and phospholipid due to the formation of a complex between them was studied by FT-IR spectroscopy. The FT-IR spectra of umbelliferone, phospholipid, complex and the physical mixture were obtained using ShimadzuIRAFFINITY-1 FT-IR spectrophotometer (Gurunanak College of pharmacy, Nagpur). The samples were triturated and mixed well with potassium bromide in the ratio 1:100. Then the mixture was introduced in the sample holder and scanned to obtain the graphs in the range of $4500-500 \mathrm{~cm}^{-1}$. Then the spectrum obtained for the complex was compared to that of the plain drug, phospholipid and their physical mixture $[27,29]$.

\section{Scanning electron microscopy (SEM)}

SEM imaging of the complex was performed by a scanning electron microscope (JEOL model JSM 6390LV) using electron beam for imaging from sophisticated analytical instrument facility, STIC, Cochin [29].

\section{X-ray diffraction study}

The crystalline behaviour of umbelliferone, phosphatidylcholine, physical mixture and the complex was evaluated using X-ray powder diffraction. Diffraction patterns were analysed with the help of Bruker AXS D8 Advance (sophisticated analytical instrument facility, STIC. Cochin). The X-ray generator was allowed to operate at $35 \mathrm{~mA}$ tube current and $40 \mathrm{kV}$ tube voltages. The scanning angle was adjusted in the range from 3 to $60^{\circ}$ in the step scan mode with a step time of $32.8 \mathrm{~s}$ [26].

\section{Nuclear magnetic resonance}

$H$-NMR-The samples of umbelliferone and complex were dissolved in the solvent dimethyl sulphoxide and analysed with a Bruker Avance II 400 NMR spectrometer (SAIF, Panjab University, Chandigarh). The spectrum was obtained and compared for the drug and complex.

${ }^{13} \mathrm{C}$-NMR-The ${ }^{13} \mathrm{C}$-NMR spectrum was taken for confirmation of the interaction between drug and phospholipid and the formation of the complex. The sample of umbelliferone and complex was dissolved in the solvent dimethyl sulphoxide and then analyzed with a Bruker Avance II 400 NMR spectrometer (SAIF, Panjab University, Chandigarh). The spectrum was obtained and compared for the drug and complex $[29,30]$.

\section{In vitro permeation}

Dialysis membrane-60 (Himedia) of diameter $15.9 \mathrm{~mm}$ was mounted on Franz diffusion cell. The receptor compartment was filled with PBS. The diffusion cell was maintained at $37 \pm 0.5^{\circ} \mathrm{C}$ with constant stirring on a magnetic stirrer. Then $1 \mathrm{ml}$ of umbelliferonephospholipid incorporated gel formulation and conventional umbelliferone gel $(0.1 \%)$ prepared similarly was spread evenly on the skin in donor compartment. Then $1 \mathrm{ml}$ sample of receptor medium was withdrawn at definite time intervals and an equivalent volume of fresh PBS were added in. All samples were filtered, diluted and analyzed by UV spectrophotometer. The permeation of the complex was compared with the plain drug [29].

\section{Animal study}

Animals-Adult Albino rats were procured from the central animal house of UDPS, R. T. M. N. U. Nagpur and used for UV protectant activity of the developed phytosome formulation as a gel. Animals were kept in plastic cages with free access to food and water and maintained at proper temperature and humidity. All the experimental protocols were approved duly by the institutional animal ethics committee (IAEC), Nagpur (India). All the experiments were performed as per the guidelines of the committee for the purpose of control and supervision of experiments on animals (CPCSEA), India. Sanction letter number-IAEC/UDPS/2014/26.

\section{Ex vivo skin permeation}

Procedure-The abdominal region of rats was shaved using a soft hair removing the cream. A full thickness abdominal skin was excised. Any adhered tissue on the skin was removed and wiped with isopropyl alcohol to remove adhered fat. It was then washed with phosphate buffer saline (PBS) of pH 7.4.

On the Franz diffusion cell, the skin was mounted properly with stratum corneum side facing the donor compartment and dermal side towards the receptor compartment. The receptor compartment was filled with buffer. The cell was maintained at $37 \pm 0.5{ }^{\circ} \mathrm{C}$ and constant stirring was implemented on a magnetic stirrer. Then $1 \mathrm{ml}$ of UMB-HSPC gel formulation and conventional UMB gel $(0.1 \%)$ which was similarly prepared was evenly spread on the skin in donor compartment. After that, $1 \mathrm{ml}$ sample from receptor medium was withdrawn at a predetermined time interval which was compensated by an equivalent volume of fresh buffer. All samples were filtered, suitably diluted and analysed by UV spectrophotometer. The permeation of the complex through the skin was compared with the plain drug [27, 28, 31, 32]. 
Evaluation of photoprotective potential of the phytosomal complex against UV exposure

Philips UV lamp ( $125 \mathrm{~W}$ ) was used for the UV exposure. A demarcated area on the dorsal surface of $\left(2 \times 3 \mathrm{~cm}^{2}\right)$ the rat was shaved using a soft hair-removing cream. The rats were observed for $48 \mathrm{~h}$. This was done to identify and exclude those rats which show abnormal hair growth or an irritation reaction to depilatory preparation. UV exposure for $20 \mathrm{~min}$ was given to the rats in this study.

Six groups of the experimental rats were formed. A thin and uniform layer of gel formulation was applied to the demarcated shaved area of the rats. Animals of the control group and UVA irradiated group were applied placebo formulation. UMB1 and UMB2 groups were applied conventional umbelliferone gel (containing $0.1 \%$ drug). UMB-HSPC1 and UMB-HSPC2 groups were applied umbelliferoneHSPC loaded gel (containing complex equivalent to $0.1 \%$ drug). UV irradiated, UMB1 and UMB-HSPC1 groups were given exposure to UV radiation immediately after topical application for $7 \mathrm{~d}$. UMB2 and UMB-HSPC2 groups were exposed to UV radiation after $4 \mathrm{~h}$ of topical application for $7 \mathrm{~d}$. On the eighth day, diethyl ether induced anaesthesia was used to sacrifice all the rats. The UV-exposed portion of cutaneous tissue was removed quickly in ice-cold saline, washed with ice-cold saline and the homogenate was prepared in $0.1 \mathrm{M}$ phosphate buffered saline ( $\mathrm{pH} 7.4)[27,33]$.

\section{Estimation of antioxidant enzymes}

The rat skin $\left(2 \times 3 \mathrm{~cm}^{2}\right)$ was washed in ice-cold saline kept in PBS and cut into small pieces. It was homogenised immediately in a homogenizer under the cold condition and centrifuged (R 24 Remi research centrifuge) to obtain $10 \% \mathrm{w} / \mathrm{v}$ supernatant skin tissue homogenate. The supernatant homogenate was used for the assay of antioxidant marker enzyme namely reduced glutathione (GSH), superoxide dismutase (SOD), catalase (CAT) and lipid peroxidation (LPO) [29, 34-38].

\section{Stability study}

A short term chemical stability of the Umbelliferone-phospholipid complex was examined for three months at $30 \pm 2{ }^{\circ} \mathrm{C}$ at $65 \pm 5 \% \mathrm{RH}$. The complex samples were analysed at an interval of $30 \mathrm{~d}$ for $3 \mathrm{mo}$ and the in vitro permeation was compared [39]. This data was statistically analysed and validated by using ANOVA.

\section{RESULTS}

\section{Pre-formulation studies}

Identification-When the filter paper was examined under UV radiation it showed blue fluorescence. The melting point range by Thiele tube method was found to be $232.1-234.3^{\circ} \mathrm{C}$.

The $\lambda_{\max }$ of umbelliferone in methanol was found to be $324 \mathrm{~nm}$. The regression equation and correlation coefficient for calibration in methanol, water and 7.4pH PBS and calibration curves are shown in fig. 1. The FT-IR spectrum of umbelliferone showed characteristic peaks.

The DSC graph of umbelliferone showed an exothermic peak and phase transition from solid at $235.34{ }^{\circ} \mathrm{C}$ to liquid at $243.45{ }^{\circ} \mathrm{C}$. The validation parameters were as per the ICH guidelines. The linearity range was $2-10 \mu \mathrm{g} / \mathrm{ml}$.

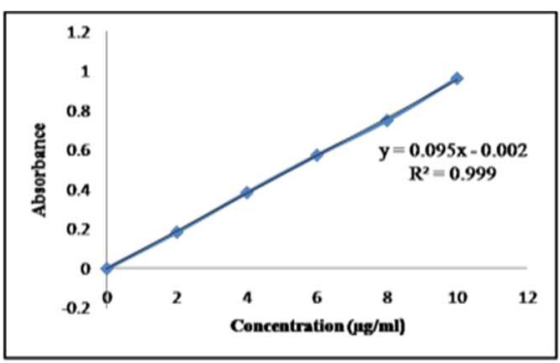

(a)

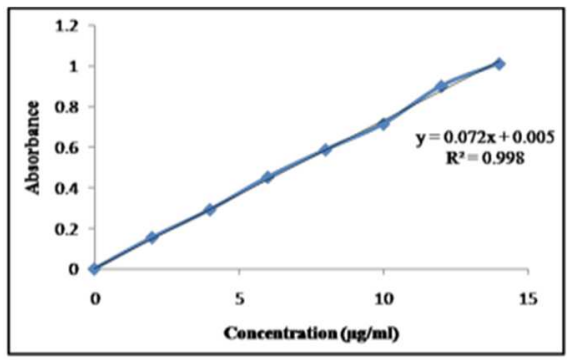

(b.)

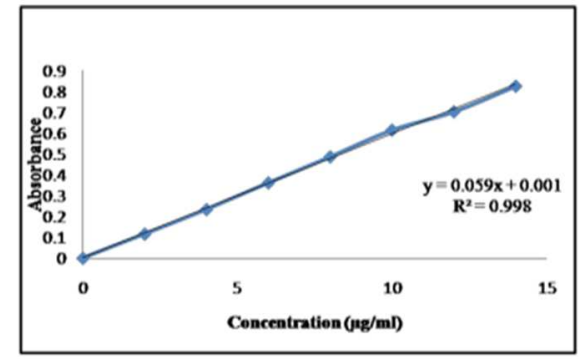

(c.)

Fig. 1: Calibration curves in methanol at $324 \mathrm{~nm}$ (a.), water at $324 \mathrm{~nm}$ (b.) and phosphate buffer saline at $341 \mathrm{~nm}$ (c.) showing regression equation and correlation coefficients of umbelliferone

\section{Preparation of umbelliferone-phospholipid complex i.e. phytosome (Box-Behnken design)-}

The optimised batch was found by evaluating two responsescomplexation rate $\left(\mathrm{Y}_{1}\right)$ and partition coefficient $\left(\mathrm{Y}_{2}\right)$. The results were as summarised in table 2 and the predicted and observed values in table 3 .

The desirability for the optimised batch (F4) was maximum 0.992 . Regression equation of the fitted quadratic model for both the responses was as follows-

$\mathrm{Y}_{1}=99.95+0.017 \mathrm{X}_{1}+0.062 \mathrm{X}_{2}-0.063 \mathrm{X}_{3}-7.35 \mathrm{X}_{1} \mathrm{X}_{2}+1.325 \mathrm{X}_{1} \mathrm{X}_{3}+0.12 \mathrm{X}_{2} \mathrm{X}_{3}$ $+0.045 \mathrm{X}_{1}{ }^{2}-0.079 \mathrm{X}_{2}{ }^{2}-0.047 \mathrm{X}_{3}{ }^{2}$

\author{
$\mathrm{Y}_{2}=14.54-4.07 \mathrm{X}_{1}+2.34 \mathrm{X}_{2}+5.79 \mathrm{X}_{3}-2.25 \mathrm{X}_{1} \mathrm{X}_{2}-6.65 \mathrm{X}_{1} \mathrm{X}_{3}+1.57 \mathrm{X}_{2} \mathrm{X}_{3}-$ \\ $4.42 \mathrm{X}_{1}{ }^{2}-1.67 \mathrm{X}_{2}^{2}+2.81 \mathrm{X}_{3}^{2}$
}

The contour plots and 3D response curves were obtained as shown in fig. 2.

\section{Complexation rate}

On the basis of highest complexation rate i.e. $99.9572 \%$, batch F4 was found to be the optimised batch (table 2).

\section{Determination of solubility by partition coefficient method}

The comparative solubility was summarised for all the batches in table 2 . 


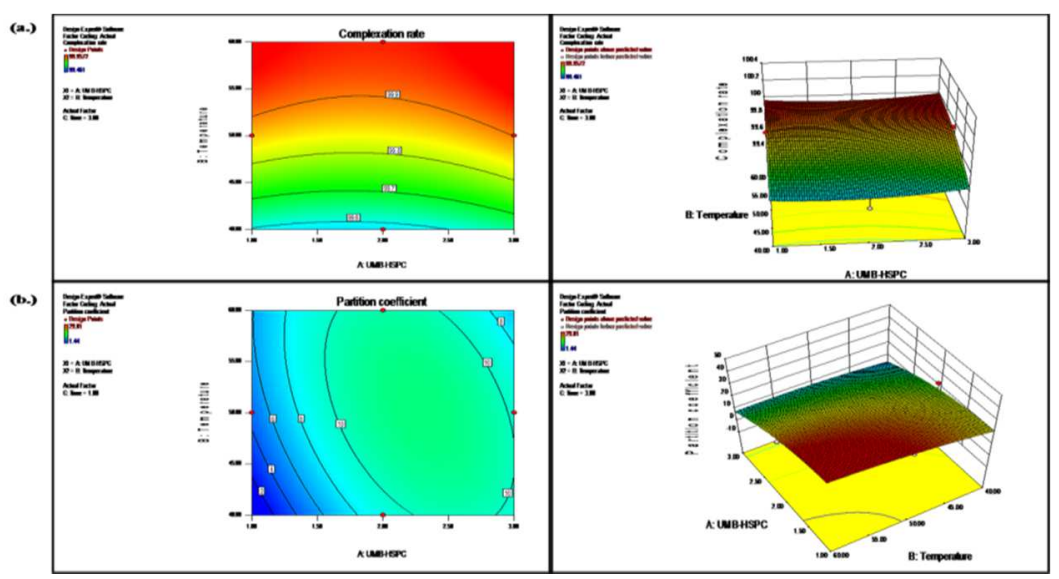

Fig. 2: Contour plots and 3D surface curves for responses-complexation rate (a) and partition coefficient (b)

Table 2: Optimization of phytosomal formulation using Box-Behnken design

\begin{tabular}{lllllll}
\hline Batch & $\mathbf{X}_{\mathbf{1}}$ & $\mathbf{X}_{\mathbf{2}}$ & $\mathbf{X}_{\mathbf{3}}$ & $\begin{array}{l}\text { Complexation rate } \\
(\mathbf{\%})\end{array}$ & $\begin{array}{l}\text { Concentration in water }\left(\mathbf{C}_{\mathbf{w}}\right) \\
(\boldsymbol{\mu g} / \mathbf{m l})\end{array}$ & $\begin{array}{l}\text { Concentration in oil }\left(\mathbf{C}_{\mathbf{o}}\right) \\
(\boldsymbol{\mu g} / \mathbf{m l})\end{array}$ \\
\hline F1 & $1: 2$ & 50 & 2 & $99.9506 \pm 0.27$ & $104.72 \pm 1.22$ & $668.42 \pm 1.43$ \\
F2 & $1: 3$ & 50 & 3 & $99.9559 \pm 0.22$ & $109.44 \pm 1.43$ & $954.00 \pm 1.50$ \\
F3 & $1: 2$ & 40 & 3 & $99.9562 \pm 0.32$ & $103.75 \pm 1.68$ & $1196.53 \pm 1.98$ \\
F4 & $1: 2$ & 60 & 3 & $99.9572 \pm 0.21$ & $140.97 \pm 1.55$ & $920.42 \pm 1.68$ \\
F5 & $1: 1$ & 50 & 1 & $99.9435 \pm 0.24$ & $137.78 \pm 1.82$ & $850.84 \pm 1.85$ \\
F6 & $1: 1$ & 40 & 2 & $99.9400 \pm 0.21$ & $100.83 \pm 1.44$ & $703.68 \pm 1.77$ \\
F7 & $1: 3$ & 60 & 2 & $99.9482 \pm 0.22$ & $82.08 \pm 1.29$ & $610.65 \pm 1.23$ \\
F8 & $1: 2$ & 60 & 1 & $99.9407 \pm 0.19$ & $78.19 \pm 1.55$ & $793.58 \pm 1.76$ \\
F9 & $1: 2$ & 50 & 2 & $99.9408 \pm 0.24$ & $53.19 \pm 2.04$ & $832.95 \pm 1.49$ \\
F10 & $1: 1$ & 50 & 3 & $99.8566 \pm 0.18$ & $34.72 \pm 1.98$ & $732.27 \pm 1.65$ \\
F11 & $1: 1$ & 60 & 2 & $99.8937 \pm 0.22$ & $33.47 \pm 1.74$ & $668.74 \pm 1.55$ \\
F12 & $1: 2$ & 40 & 1 & $99.9303 \pm 0.36$ & $46.67 \pm 1.43$ & $1071.47 \pm 1.83$ \\
F13 & $1: 2$ & 50 & 2 & $99.9446 \pm 0.26$ & $48.33 \pm 1.87$ & $1000.11 \pm 1.48$ \\
F14 & $1: 3$ & 40 & 2 & $99.9481 \pm 0.28$ & $39.17 \pm 1.32$ & $1136.32 \pm 1.06$ \\
F15 & $1: 3$ & 50 & 1 & $99.9461 \pm 0.016$ & $40.69 \pm 1.92$ & 9.98 \\
\hline
\end{tabular}

Data is presented as mean value $\pm \operatorname{SD}(n=3)$

Table 3: Observed and predicted values of optimized batch

\begin{tabular}{lll}
\hline Response & Predicted values & Observed values (Optimized batch F4) \\
\hline Complexation rate & $99.9424 \pm 0.02$ & $99.9572 \pm 0.21$ \\
Partition coefficient & 7.98 & 6.52 \\
\hline
\end{tabular}

Table 4: In vitro antioxidant assay-\% DPPH radical scavenging activity and \% ferrozine antioxidant assay

\begin{tabular}{llll}
\hline $\begin{array}{l}\text { Concentration } \\
(\boldsymbol{\mu g} / \mathbf{m l})\end{array}$ & $\begin{array}{l}\text { \%DPPH scavenging activity } \\
\text { for umbelliferone }\end{array}$ & $\begin{array}{l}\text { \%DPPH scavenging } \\
\text { activity for complex }\end{array}$ & $\begin{array}{l}\text { \% Ferrozine antioxidant } \\
\text { activity for umbelliferone }\end{array}$ \\
\hline 10 & $35.269 \pm 1.65$ & $30.4414 \pm 1.55$ & $\begin{array}{l}\text { \% Ferrozine antioxidant } \\
\text { activity for complex }\end{array}$ \\
20 & $35.8033 \pm 1.68$ & $36.5984 \pm 1.84$ & $95.370 \pm 1.03$ \\
30 & $35.0846 \pm 1.72$ & $35.7461 \pm 1.75$ & $96.6524 \pm 1.26$ \\
40 & $35.8606 \pm 1.55$ & $36.1214 \pm 1.89$ & $97.2075 \pm 1.12$ \\
50 & $36.4203 \pm 1.53$ & $36.5475 \pm 1.79$ & $94.1240 \pm 1.54$ \\
60 & $35.797 \pm 1.76$ & $36.0514 \pm 1.66$ & $93.2217 \pm 1.48$ \\
70 & $34.9051 \pm 1.42$ & $35.5489 \pm 1.65$ & $90.2066 \pm 1.62$ \\
80 & $34.8542 \pm 1.66$ & $35.4535 \pm 1.73$ & $81.1615 \pm 1.29$ \\
90 & $33.9814 \pm 1.58$ & $35.6952 \pm 1.63$ & $73.1385 \pm 1.49$ \\
\hline
\end{tabular}

Data is presented as mean value $\pm \operatorname{SD}(n=3)$

\section{Characterization of complex}

\section{Percentage practical yield}

The percentage practical yield of the optimized batch F4 was found to be $96.064 \%$

\section{Drug content}

The drug content of umbelliferone in the phytosomal complex for optimised batch F4 was found to be $97.40 \%$.

\section{In vitro antioxidant activity}

The results for DPPH and Ferrozine antioxidant activity of newly prepared phytosomal delivery system are shown in table 4 and the comparative antioxidant activity for drug and complex is shown in the fig. 3 .

\section{HPTLC of the complex and drug}

The peak for the plain drug was found to be sharp whereas the peak for the complex was found to be broader as shown in fig. 4 . The $\mathrm{R}_{\mathrm{f}}$ value of the complex was 0.32 , and that of umbelliferone was 0.33 . 

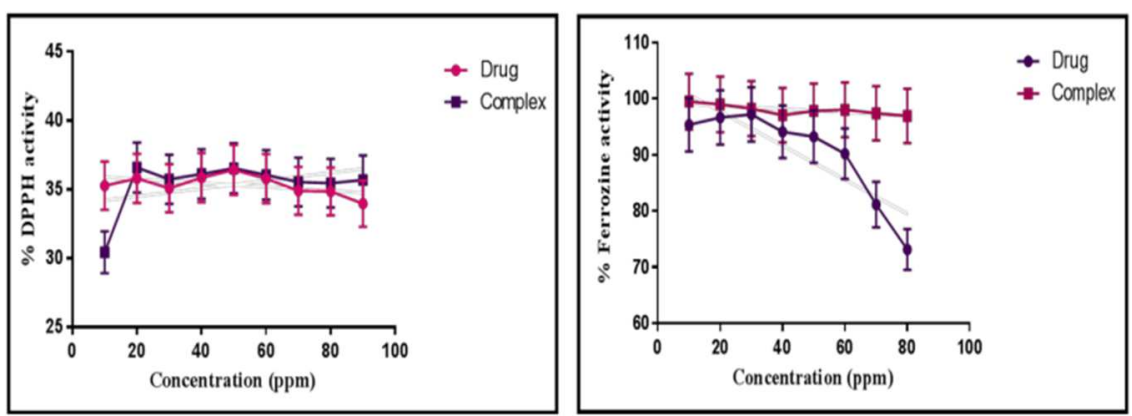

Fig. 3: In vitro antioxidant assay-\% DPPH radical scavenging activity and \% ferrozine antioxidant assay
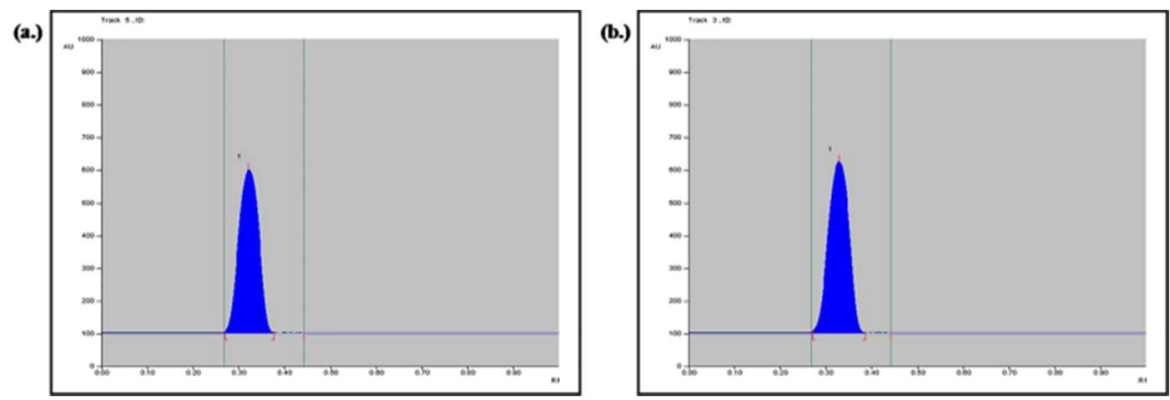

Fig. 4: Chromatograms for umbelliferone, $R_{f}=0.33$ (a.) and complex, $R_{f}=0.32$ (b.)

\section{Particle size and zeta potential}

The average particle size was found to be $1139 \mathrm{~nm}$ and the range was between $200-2600 \mathrm{~nm}$. The polydispersity index was found to be 0.717 indicating uniform particle size. The zeta potential of complex was- $0.05 \mathrm{mV}$ as shown in fig. 5 .

\section{Differential scanning calorimetry}

Umbelliferone showed an exothermic peak ranging from 235.34$243.52^{\circ} \mathrm{C}$. Phosphatidylcholine showed a major peak at $84.83^{\circ} \mathrm{C}$ and another peak at $67.16^{\circ} \mathrm{C}$. The physical mixture showed peaks at $283.73{ }^{\circ} \mathrm{C}$ indicating little interaction. The complex showed a peak at $75.17{ }^{\circ} \mathrm{C}$. Moreover, the onset temperature was $63.55{ }^{\circ} \mathrm{C}$ only as shown in fig. 6.

\section{FT-IR spectroscopy}

The FT-IR spectrum of umbelliferone showed a sharp peak of $\mathrm{OH}$ group at $3182.55 \mathrm{~cm}^{-1}$. It showed $\mathrm{C}=0$ stretch at $1726.29 \mathrm{~cm}^{-1}$, aromatic C-H stretch from $3061.03-3084.18 \mathrm{~cm}^{-1}$ and aromatic $\mathrm{C}=\mathrm{C}$ stretch. The spectrum of phosphatidylcholine showed

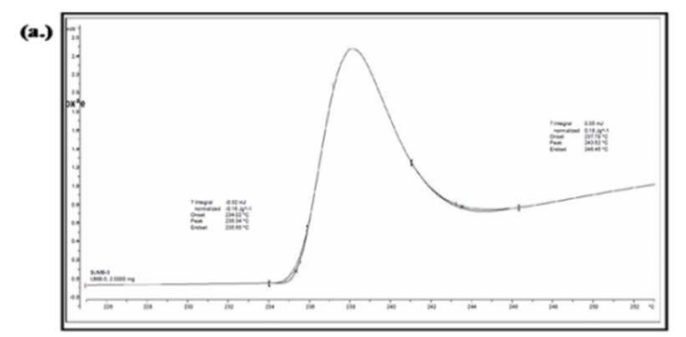

(c.)

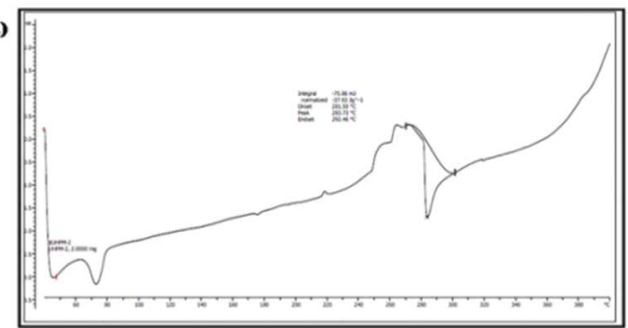

characteristic $\mathrm{C}-\mathrm{H}$ stretching band of long fatty acid chain at 2918.3 and $2854.96 \mathrm{~cm}^{-1}$, carbonyl stretching band at 1728.22 $\mathrm{cm}^{-1}$ in the fatty acid ester, $\mathrm{P}=0$ stretching band at $1236.37 \mathrm{~cm}^{-1}$ $\mathrm{P}-\mathrm{O}-\mathrm{C}$ stretching band at $1093.65 \mathrm{~cm}^{-1}$, and $\mathrm{N}^{+}\left(\mathrm{CH}_{3}\right)_{3}$ stretching at $966.34 \mathrm{~cm}^{-1}$. The spectrum of the complex showed significant changes, and the absorption peak of hydroxyl stretching of umbelliferone showed remarkable broadening from 3223.05$3331.07 \mathrm{~cm}^{-1}$ as depicted in fig. 7.

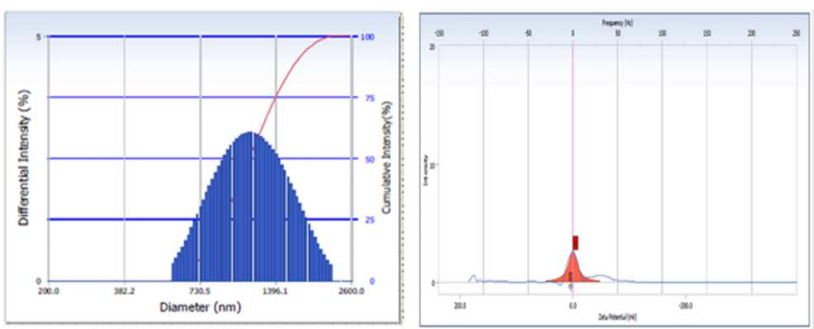

Fig. 5: Particle size and zeta potential for the complex
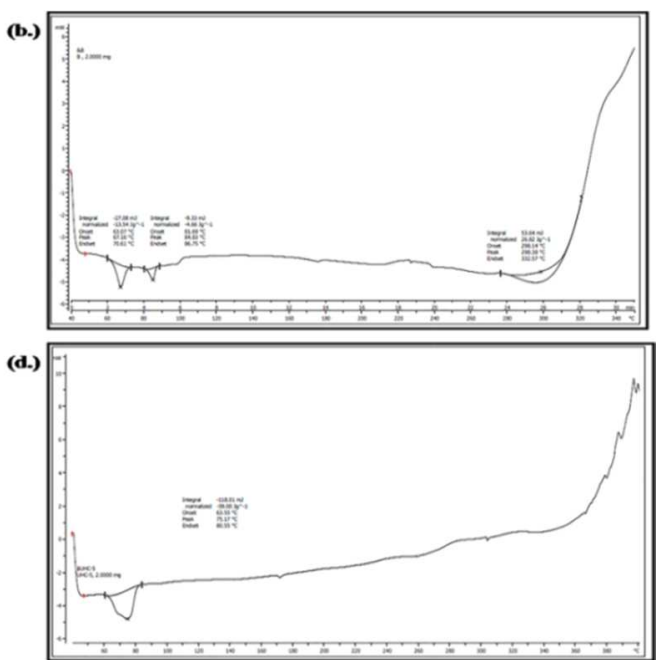

Fig. 6: Differential scanning calorimetry thermograms of umbelliferone (a), phosphatidylcholine (b), physical mixture (c) and complex (d) 

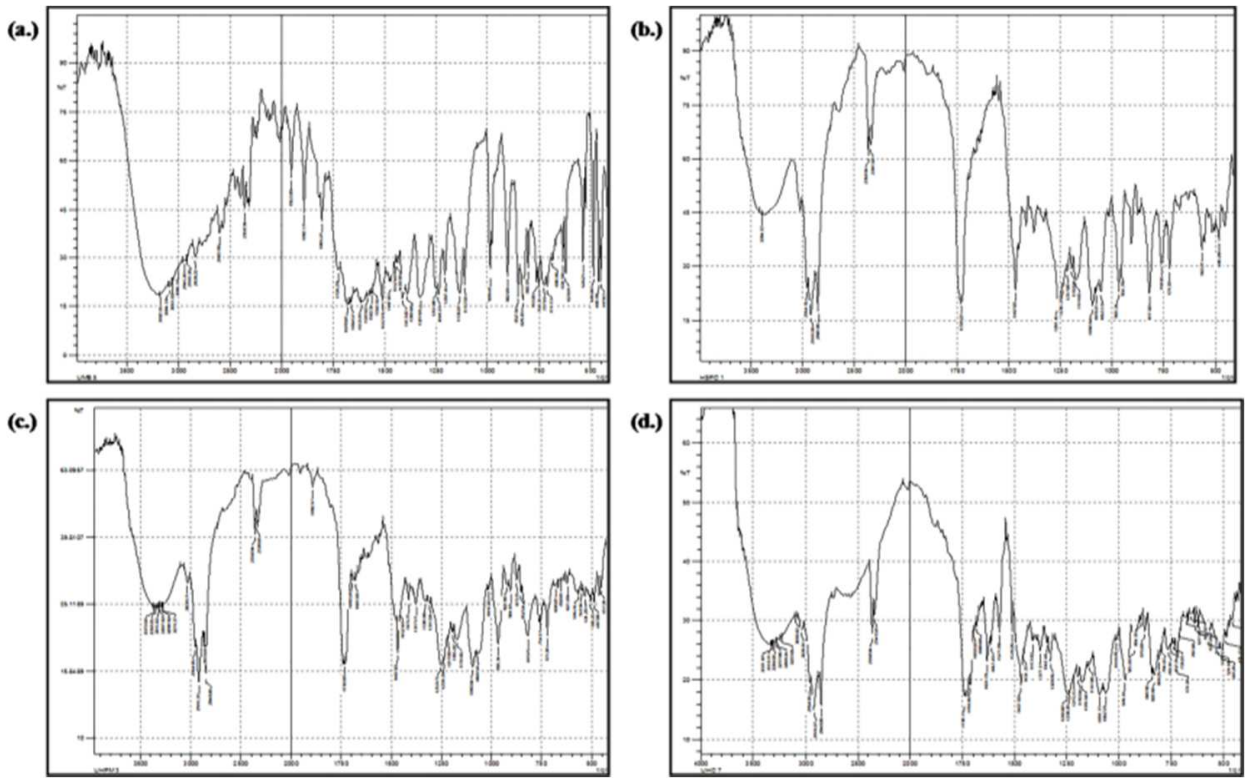

Fig. 7: FT-IR spectra of umbelliferone (a), phosphatidylcholine (b), physical mixture (c) and complex (d)

\section{Scanning electron microscopy}

Fig. 8 depicts the micrograph showing the surface morphology of the complex and drug.

\section{X-ray diffraction study}

X-ray diffractogram of umbelliferone showed intense sharp diffraction peaks of crystallinity at a diffraction angle $(2 \theta)$ of 15.834 . The phospholipid showed a single intense peak at $2 \theta$ value of 21.242 . The physical mixture showed a less intense and broader peak from $2 \theta$ values 13.901-32.635. X-ray diffraction pattern of the complex showed peaks from $2 \theta$ value 15.681 to 27.618 as shown in fig. 9.

\section{Nuclear magnetic resonance}

$H$-NMR-fig. 10 shows the H-NMR spectrum of umbelliferone with a value of $\delta 2.5328$ indicating (d, $1 \mathrm{H}, \mathrm{H}-3$ equatorial) hydrogen at position 3. The value of $\delta 2.52$ was for (dd, $1 \mathrm{H}, \mathrm{H}-4$ equatorial) hydrogen at position 4 . The value of $\delta 10.45$ was distinct for $(\mathrm{s}, 1 \mathrm{H}$, 7-OH) hydroxyl group of umbelliferone. The H-NMR spectrum of complex showed $\delta 0.863$.
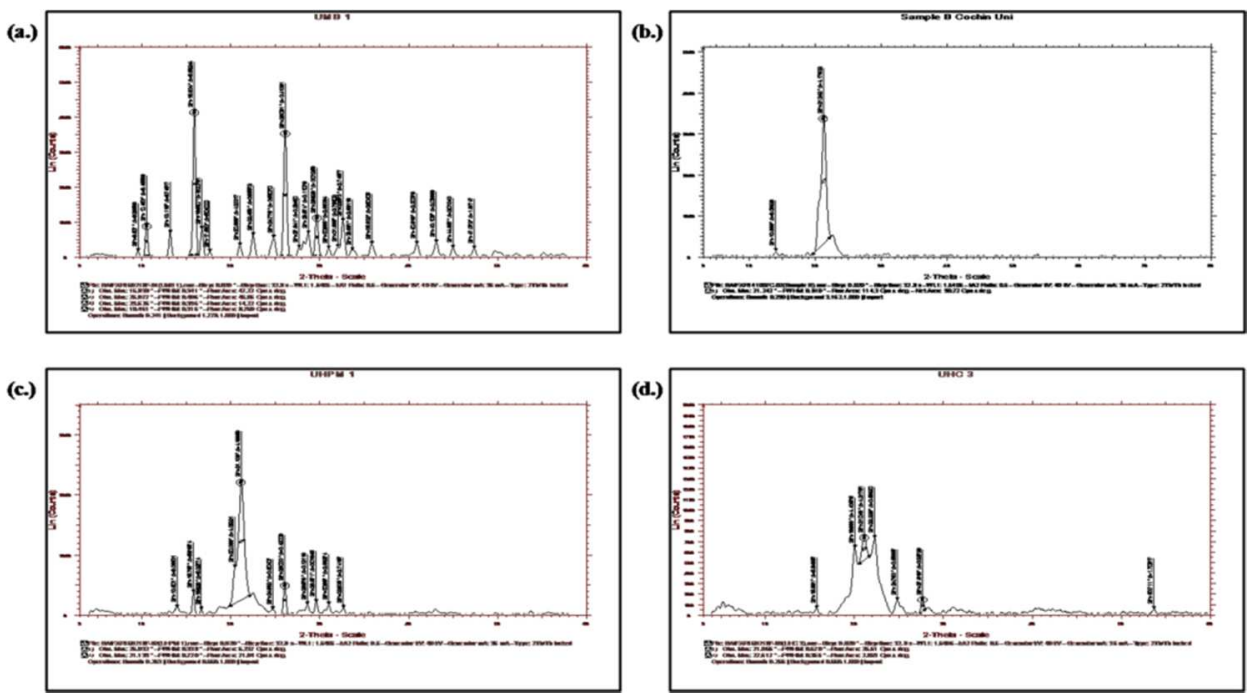

Fig. 9: X ray diffractograms of umbelliferone (a), phosphatidylcholine (b), physical mixture (c) and complex (d)
${ }^{13} \mathrm{C}$-NMR-fig. 10 shows the ${ }^{13} \mathrm{C}$-NMR spectrum of umbelliferone with the signal at $\delta 155.57 \mathrm{ppm}$ for carbon with a hydroxyl group. It showed a signal at $\delta$ value $138.59 \mathrm{ppm}$ for carbon with a carbonyl group. It also showed signals for aromatic rings from $\delta 107.32$ to $155.57 \mathrm{ppm}$. The spectrum of the complex showed signals on the higher side indicating a chemical shift from $\delta 155.57$ to $160.39 \mathrm{ppm}$.

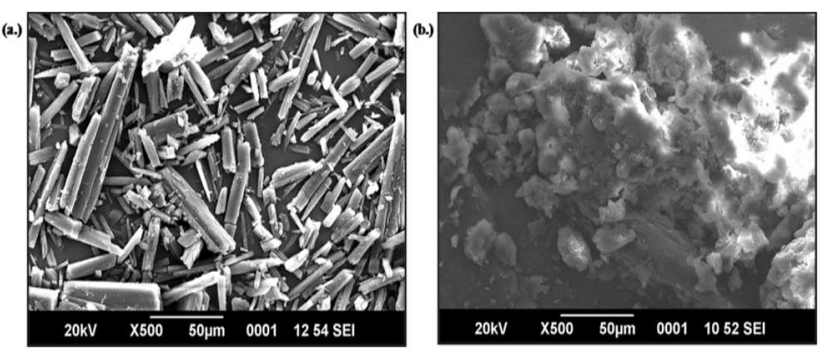

Fig. 8: Scanning electron microscopy images of umbelliferone (a) and complex (b) 


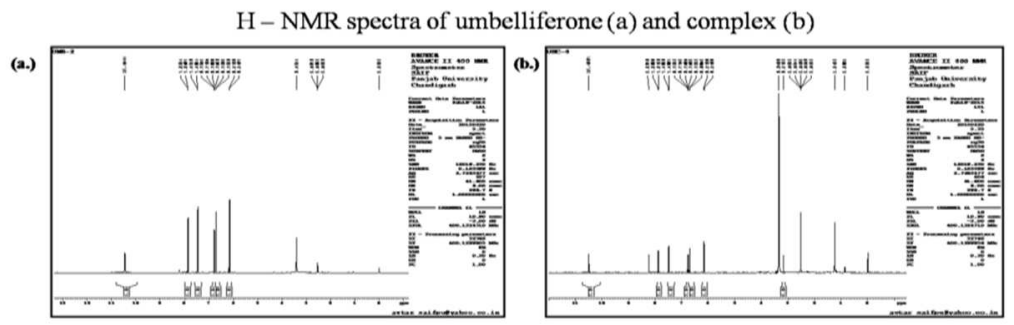

${ }^{13} \mathrm{C}-\mathrm{NMR}$ spectra of umbelliferone (a) and complex (b)

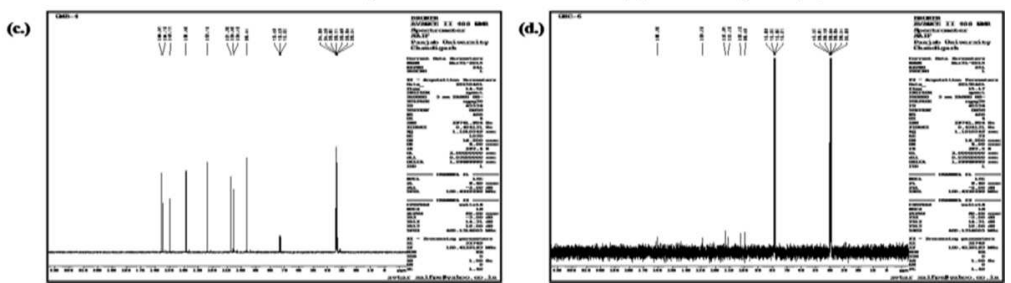

Fig. 10: Nuclear magnetic resonance spectrums of umbelliferone and complex

\section{Ex vivo and in-vitro permeation}

The results for percent cumulative release of drug and phytosomal complex through membrane and skin are given in table 5 and comparison was depicted in fig. 11.

Evaluation of photoprotective potential of the complex against UV exposure and estimation of antioxidant enzymes

For each group, the mean \pm SEM values were calculated. The data was analysed using Graph pad software version 5 by one-way ANOVA and the groups were compared using Dunnet test. The amount of enzymes found were summarised in the table 6 and compared for all groups in the fig. 12 .

\section{Stability study}

Table 7 shows the results obtained for the stability study.

\section{DISCUSSION}

Development of valuable drug delivery system from natural sources is very much necessary because of the beneficial role of herbal drugs in the management of various diseases [40]. Blue fluorescence is the characteristic property of coumarin and its derivatives. The coumarin ring allows the material to fluorescence under ultraviolet radiation making it a property for specific identification and as umbelliferone showed blue fluorescence it indicated its specific nature [10].

Table 5: Ex vivo and in vitro permeation study

\begin{tabular}{|c|c|c|c|c|}
\hline Time (minutes) & Ex vivo \%CR of umbelliferone & Ex vivo \%CR of complex & In vitro \%CR of umbelliferone & In vitro \%CR of complex \\
\hline 60 & $9.6271 \pm 1.62$ & $5.8601 \pm 1.87$ & $21.7627 \pm 1.23$ & $16.1228 \pm 1.89$ \\
\hline 120 & $14.1520 \pm 1.30$ & $11.5733 \pm 1.54$ & $24.5313 \pm 1.54$ & $21.9245 \pm 1.65$ \\
\hline 180 & $20.9061 \pm 2.11$ & $17.6074 \pm 1.43$ & $28.2788 \pm 1.65$ & $30.9113 \pm 1.44$ \\
\hline 240 & $28.0989 \pm 1.65$ & $19.6232 \pm 1.66$ & $41.5830 \pm 1.87$ & $36.3718 \pm 1.76$ \\
\hline 300 & $33.6620 \pm 1.89$ & $24.7137 \pm 2.34$ & $52.5042 \pm 1.49$ & $43.5037 \pm 1.54$ \\
\hline 360 & $39.4096 \pm 2.23$ & $30.1481 \pm 1.98$ & $56.9359 \pm 2.06$ & $46.8203 \pm 2.98$ \\
\hline 420 & $46.2700 \pm 1.54$ & $36.8861 \pm 2.04$ & $61.9044 \pm 1.68$ & $49.0920 \pm 1.02$ \\
\hline 480 & $61.0176 \pm 1.84$ & $42.7791 \pm 1.66$ & $69.7449 \pm 1.71$ & $56.9183 \pm 1.51$ \\
\hline 540 & $72.0101 \pm 1.33$ & $46.9396 \pm 1.84$ & $77.9617 \pm 1.44$ & $63.7703 \pm 1.69$ \\
\hline 600 & $100.0710 \pm 1.76$ & $54.2533 \pm 1.67$ & $99.2683 \pm 2.11$ & $69.3027 \pm 1.84$ \\
\hline 660 & - & $58.1376 \pm 1.49$ & - & $76.9632 \pm 2.14$ \\
\hline 720 & - & $67.7248 \pm 1.88$ & - & $89.2666 \pm 1.23$ \\
\hline 1440 & - & $96.9500 \pm 2.32$ & - & $100.7873 \pm 1.36$ \\
\hline
\end{tabular}

Data is presented as mean value $\pm \operatorname{SD}(n=3)$
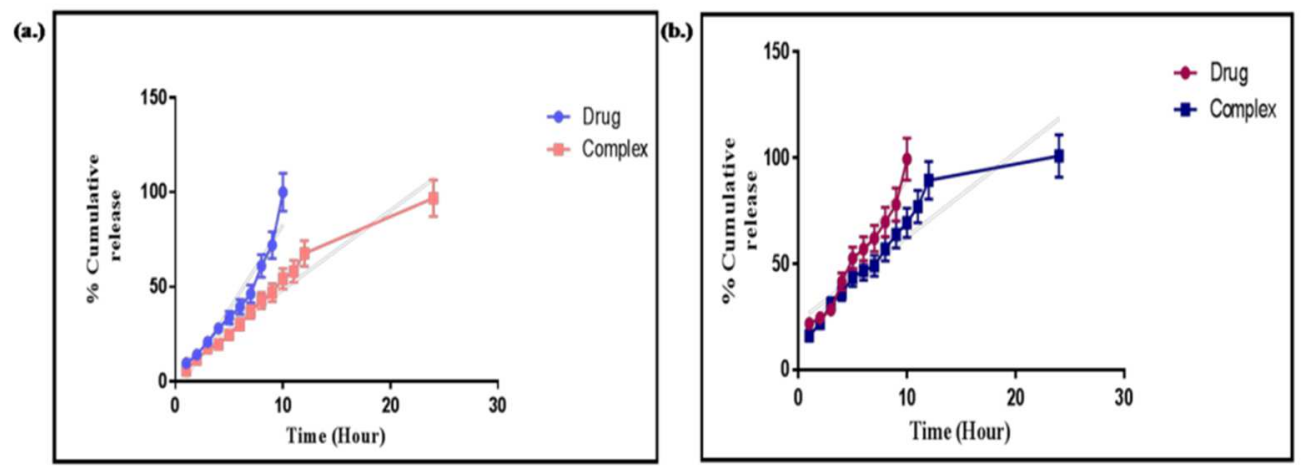

Fig. 11: Ex vivo (a.) and in vitro (b.) permeation study of umbelliferone and complex 
(a.)

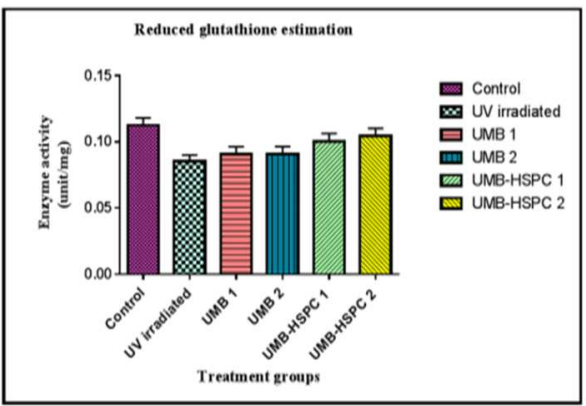

(c.)

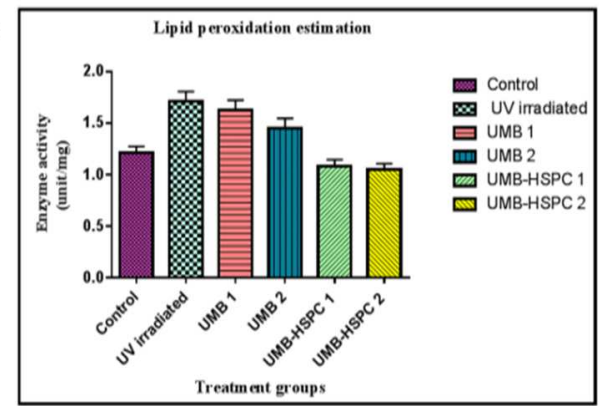

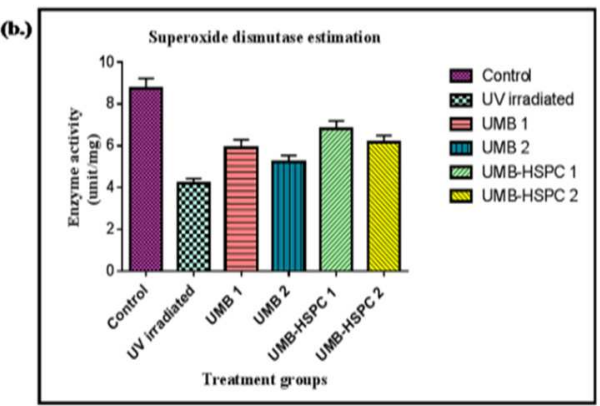

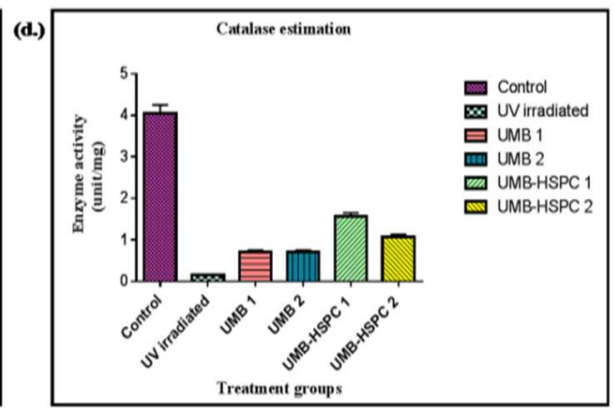

Fig. 12: Effect of UV exposure on the antioxidant enzymes-GSH (a), SOD (b), LPO (c) and CAT (d)

Table 6: Estimation of antioxidant enzymes

\begin{tabular}{|c|c|c|c|c|}
\hline Treatment groups & $\begin{array}{l}\text { GSH (Unit/mg wet } \\
\text { tissue) }\end{array}$ & $\begin{array}{l}\text { SOD (Unit/mg wet } \\
\text { tissue) }\end{array}$ & $\begin{array}{l}\text { LPO (Unit/mg wet } \\
\text { tissue) }\end{array}$ & $\begin{array}{l}\text { CAT (Unit/mg wet } \\
\text { tissue) }\end{array}$ \\
\hline Control & $0.1126 \pm 0.0056$ & $8.7415 \pm 0.4807$ & $1.213 \pm 0.0606$ & $4.0502 \pm 0.20$ \\
\hline UV irradiated & $0.0854 \pm 0.0047$ & $4.1823 \pm 0.2509$ & $1.711 \pm 0.0941$ & $0.1604 \pm 0.008$ \\
\hline $\begin{array}{l}\text { Umbelliferone gel (Immediate UV } \\
\text { treatment) }\end{array}$ & $0.0909 \pm 0.0055$ & $5.9018 \pm 0.3836$ & $1.625 \pm 0.0975$ & $0.7066 \pm 0.042$ \\
\hline $\begin{array}{l}\text { Umbelliferone gel (UV treatment } \\
\text { after } 4 \mathrm{~h} \text { ) }\end{array}$ & $0.0907 \pm 0.0059$ & $5.2145 \pm 0.3128$ & $1.451 \pm 0.0943$ & $0.7013 \pm 0.045$ \\
\hline $\begin{array}{l}\text { Complex gel (Immediate UV } \\
\text { treatment) }\end{array}$ & $0.1003 \pm 0.0060$ & $6.8103 \pm 0.3745$ & $1.081 \pm 0.0648$ & $1.555 \pm 0.093$ \\
\hline Complex gel (UV treatment after $4 \mathrm{~h}$ ) & $0.1044 \pm 0.0057$ & $6.1752 \pm 0.3087$ & $1.05 \pm 0.05775$ & $1.0721 \pm 0.058$ \\
\hline
\end{tabular}

Data is presented as mean value $\pm S$. $D(n=6)$

Table 7: Stability study

\begin{tabular}{|c|c|c|c|}
\hline Formulation & Storage conditions & Time interval (Months) & In vitro release after $12 \mathrm{~h}(\%)$ \\
\hline \multirow[t]{4}{*}{ Umbelliferone-Phospholipon 90H complex (Batch 4) } & $30 \pm 2^{\circ} \mathrm{C}$ and & 0 & $89.26 \pm 1.23$ \\
\hline & $65 \pm 5 \%$ RH & 1 & $87.33 \pm 1.97$ \\
\hline & & 2 & $90.11 \pm 1.44$ \\
\hline & & 3 & $89.59 \pm 2.04$ \\
\hline
\end{tabular}

Data is presented as mean value $\pm S$. $D(n=3)$

The melting point by Thiele tube method complied with the standard value. The regression equation for the calibration curves in all the solvents followed Lambert-Beer's law and the correlation coefficient was found to be near 1 depicting linear relationship. The linearity parameter and the corresponding regression data indicated good linear relationship for quantification method. The validation parameters confirmed the adequate sample stability, accuracy and method reliability and the observed \% RSD was $<2 \%$ as per ICH guidelines $[10,15]$.

Phospholipids play a major role in drug delivery and have numerous advantages in addition to solubilizing property while considering them for a carrier system [40]. The umbelliferone-phospholipid complex was prepared using solvent evaporation method by applying the Box-Behnken design. The quadratic equation for each response was obtained and only statistically significant coefficients $\left(\mathrm{p}=0.0405\right.$ for $\mathrm{Y}_{1}$ and $\mathrm{p}=0.0483$ for $\mathrm{Y}_{2}$ ) were included and a positive coefficient indicated that the response is favored, while a negative value indicated an inverse relationship between the factor and response. It was clear from the equations that umbelliferone: phospholipon ratio $\left(\mathrm{X}_{1}\right)$, temperature $\left(\mathrm{X}_{2}\right)$ had positive relationship and time $\left(\mathrm{X}_{3}\right)$ had an inverse relationship on complexation rate $\left(\mathrm{Y}_{1}\right)$. On the other hand, temperature $\left(X_{2}\right)$ and time $\left(X_{3}\right)$ had a positive relationship and phospholipon: umbelliferone ratio $\left(\mathrm{X}_{1}\right)$ had an inverse relationship on partition coefficient $\left(\mathrm{Y}_{2}\right)$ [16].

On the basis of highest complexation rate i.e. $99.9572 \%$, batch F4 was found to be the optimized batch, and the complexation rate depicted a good affinity of phospholipid towards the drug. The solubility was found to increase for the complex as compared to the drug in both the phases. This may be attributed to the fact that the complex formed was amphiphilic in nature possessing hydrophilic choline group which bound with the hydroxyl group of the drug while the lipid soluble phosphatidyl moiety enveloped the choline 
bound material, leading to better solubility in both phases. The higher values indicated good practical yield after complexation and maximum recovery [17].

The high drug content depicted maximum entrapment in the complex which indicated a stable complex of umbelliferone with phospholipid [18]. The \% DPPH radical scavenging activity and the $\%$ Ferrozine antioxidant activity of the complex was better than that of the drug because the complex had a better ability for scavenging oxidative free radicals than the drug owing to its amphiphilic and stable nature [19-23]. HPTLC study depicted distinct $R_{f}$ value for the complex and the drug, which indicated the successful formation of the complex [25]. The particle size range between 200-2600 $\mathrm{nm}$ indicated uniform particle size for the complex and the zeta potential of $-0.05 \mathrm{mV}$ indicated the formation of a stable complex [17].

DSC exothermic peak of umbelliferone indicated a phase transition. The thermogram of the physical mixture showed a little interaction. The original peaks of umbelliferone and phosphatidylcholine disappeared from the thermogram of the complex, and the phase transition temperature was lower than that of phospholipid indicating the successful formation of the complex [26]. The FT-IR spectrum of the physical mixture was found to be the summation of the spectra of drug and lipid. The FT-IR spectrum of complex showed a broadening of peaks of a hydroxyl group which indicated interaction of the drug with the phospholipid and formation of the complex [41].

SEM showed that the crystalline drug was completely converted into the amorphous form on complexation owing to the change in visual sharpness to blunt structure. This can be attributed to the solubility data which showed higher solubility for the complex than drug [29].

X-ray diffraction study indicated that the sharp peak of umbelliferone owed to its crystalline nature. The physical mixture showed less intense and broad peaks which indicated transformation into an amorphous form. Complete conversion into amorphous form was indicated by the large diffused peaks of complex [29].

$\mathrm{H}-\mathrm{NMR}$ results indicated that the phenolic protons were found to shift (downfield) in the complex indicating the interaction of phospholipid with the phenolic-OH group which depicted the successful formation of the complex. Similarly ${ }^{13} \mathrm{C}-\mathrm{NMR}$ study indicated that the spectrum of the complex showed values of signals on the higher side depicting a chemical shift due to the interaction of hydroxyl group with the phosphatidylcholine hydroxyl group causing a shift. The spectrum of complex showed very intense and fused signals indicating the formation of the complex $[30,42]$.

The in vitro and ex vivo skin permeation of complex from the gel was higher than the drug in ex vivo as well as in vitro permeation. Model fitting of permeation profile of drug from the UMB gel and complex loaded gel was performed using Zero order, First order, Higuchi model and Korsmeyer-Peppas model.

On the basis of the highest coefficient of correlation, the best fit was shown by zero-order drug release for both the preparations. Using the Korsmeyer-Peppas model, the value of permeation coefficient (n) for the drug and complex was obtained to be $0.5<\mathrm{n}<1$ indicating a non-Fickian pattern of drug release i.e. a combination of drug diffusion and matrix erosion [29].

In the evaluation of photoprotective potential of the complex against UV exposure, the unit/mg of reduced glutathione (GSH), superoxide dismutase (SOD) and catalase (CAT) was the highest in control group and the least in UV-irradiated group. The lipid peroxidation (LPO) was highest in UV-irradiated group and least in the group treated with complex gel. When the enzyme activity was compared for UMB gel and complex gel it was found that the enzymes were higher in the group treated with complex gel than those with UMB gel with immediate as well as with those with UV irradiation after 4 h. This may be attributed to the fact that the complex showed a better permeation than the drug. The comparison using Dunnet test was statistically significant. This indicated that the complex gel was better able to protect the skin and antioxidant enzymes from UV radiations than the plain UMB gel [34-38].

Stability study indicated that the optimised batch did not show any significant changes during the study period of three months which further indicated the formation of the stable complex on storage [39].

\section{CONCLUSION}

Umbelliferone was successfully complexed with phosphatidylcholine to form phytosome, a novel drug delivery system. The preformulation studies confirmed identification of umbelliferone and the validation parameters confirmed stability and method reliability. The complex was successfully formulated by solvent evaporation method using Box-Behnken experimental design and batch was optimised. The optimised batch was evaluated for $\%$ practical yield, complexation rate, drug content and the results were within the range. The complex showed better solubility than the drug in both phases. The complex was found to show higher in vitro antioxidant activity than the drug at the same concentrations. The HPTLC, DSC, FT-IR, SEM, XRD and NMR study confirmed the successful formation of the complex. The ex vivo and in vitro permeation studies showed better release for phytosomal complex than the drug. The animal study was carried out for the photoprotective effect of complex and the effect was evaluated by estimating the antioxidant enzymes. The phytosomal complex was better able to protect the skin and the antioxidant enzymes than the drug. The stability study revealed that there were no significant changes in the formulation over the period of three months. Hence it can be concluded that umbelliferone in novel drug delivery system i.e. phytosomal form, produces a better therapeutic effect than the drug alone.

\section{CONFLICT OF INTERESTS}

Declared none

\section{ACKNOWLEDGEMENT}

The authors would like to thank AICTE, for providing financial assistance. The authors would also like to thank all the manufacturers and suppliers for providing excipients as a gratis sample for the study. We would also like to thank the colleges and institutions responsible for analysis of the samples required for project work.

\section{REFERENCES}

1. Kalita B, Das MK, Sharma AK. Novel phytosome formulations in making herbal extracts more effective. Res J Pharm Technol 2013;6:1295-301.

2. More MS, Shende M, Kolhe DB, Jaiswal NM. Herbosomes: herbo-phospholipid complex an approach for absorption enhancement. Int J Biol Pharm Res 2012;3:946-55.

3. Choubey A. Phytosome-a novel approach for herbal drug delivery. Int J Pharm Sci Res 2011;2:807-15.

4. Chein YW. Novel Drug Delivery Systems. Second ed. 1; 2011. p. 816.

5. Sarangi MK, Padhi S. Solid lipid nanoparticles-a review. J Crit Rev 2016;3:5-12.

6. Patel J, Patel R, Khambolja K, Patel N. An overview of phytosomes as an advanced herbal drug delivery system. Asian J Pharmacol 2009;4:363-71.

7. Tripathy S, Patel DK, Baro L, Nair SK. A review on phytosomes, their characterization, advancement and potential for transdermal application. J Drug Delivery Ther 2013;3:147-52.

8. Gandhi A, Dutta A, Pal A, Bakshi P. Recent trends of phytosomes for delivering herbal extract with improved bioavailability. J Pharmacogn Phytochem 2012;1:1-14.

9. Jain N, Gupta BP, Thakur N, Jain R, Banweer J, Jain DK, et al. Phytosome: a novel drug delivery system for herbal medicine. Int J Pharm Sci Res 2010;2:224-8.

10. Malik A, Kushnoor A, Saini V, Singhal S, Kumar S, Yadav YC. Analytical method development of nutraceutical: umbelliferone. Int J Pharm Sci 2012;3:67-73.

11. Kokate CK, Purohit AP, Gokhale SB. Pharmacognosy. $31^{\text {st }}$ ed. Nirali Prakashan; 2005. p. 596. 
12. Oviya VJ, Vishnupriya V, Gayathri R. Comparative analysis of antioxidant and free radicals scavenging activity of lemongrass oil and lavender oil. Asian J Pharm Clin Res 2016;9:136-9.

13. Furniss BS, Hannaford AJ, Smith PWG, Tatchell AR. Vogel's Textbook. $5^{\text {th }}$ ed. Practical Organic Chemistry; 2008. p. 236-40.

14. Rawat MSM, Semalty A, Semalty M, Singh D. Preparation and characterization of phospholipid complexes of naringenin for effective drug delivery. Springer Sci 2010;67:253-60.

15. Singh S, Mishra A, Verma A, Ghosh AK, Mishra AK. A simple ultraviolet spectrophotometric method for the determination of etoricoxib in dosage formulations. J Adv Pharm Technol Res 2012;5:237-40

16. Saharan VA, Agarwal A, Kharb V. Process optimisation, characterization and evaluation of resveratrol-phospholipid complexes using box-behnken statistical design. Int Curr Pharm J 2014;3:301-8.

17. Tan $\mathrm{Q}$, Liu $\mathrm{S}$, Chen $\mathrm{X}, \mathrm{Wu} \mathrm{M}$, Wang $\mathrm{H}$, Yin $\mathrm{H}$, et al. Design and evaluation of a novel evodiamine-phospholipid complex for improved oral bioavailability. AAPS PharmSciTech 2012; 13:534-47.

18. Sikarwar MS, Sharma S, Jain AK, Parial SD. Preparation, characterization and evaluation of marsupsin-phospholipid complex. AAPS PharmSciTech 2008;9:129-37.

19. Nickilisch SCT, Waite JH. Optimised DPPH assay in a detergentbased buffer system for measuring antioxidant activity of proteins. Methods X, Elsevier 2014;1:233-8.

20. Santhy KS, Archana D, Dixitha M. Antioxidant and anticlastogenic potential of Piper longum L. Int J Appl Pharm 2015;7:11-4.

21. Pandey KD, Kumar A, Singh M, Singh PP, Singh SK, Raj P. Antioxidant efficacy and curcumin content of turmeric (Curcuma longa L.) flower. Int J Curr Pharm Res 2016;8:112-4.

22. Semalty A, Semalty M, Singh D, Rawat MSM. The phytophospholipid complex of catechin in value added herbal drug delivery. J Inclusion Phenom Macrocyclic Chem 2012;73:377-86

23. Dringen R, Riemer J, Hoepken HH, Czerwinska H, Robinson SR. Colorimetric ferrozine-based assay for the quantitation of iron in cultured cells. Anal Biochem Elsevier 2004; 331:370-5

24. Dhalwal K, Shinde VM, Mahadik KR, Namdeo AG. A rapid densitometric method for simultaneous analysis of umbelliferone, psoralen, and eugenol in herbal raw materials using HPTLC. J Sep Sci 2007;30:2053-8.

25. Husain A, Aamir M, Mujeeb M, Siddique NA. Simultaneous quantification of umbelliferone and quercetin in polyherbal formulations of Aegle marmelos by HPTLC. Am J PharmTech Res 2012;2:2249-3387.

26. Yue PF, Yuan H, Li X, Yang M, Zhu W. Process optimisation, characterization and evaluation in vivo of the oxymatrinephospholipid complex. Int J Pharm 2010;387:139-46.
27. Mukherjee PK, Bhattacharyya S, Majhi S, Saha BP. Chlorogenic acid-phospholipid complex improve protection against UVAinduced oxidative stress. I Photochem Photobiol B 2014;130:293-8.

28. Ahmed AB, Ahmed R, Sengupta R. Formulation and in vitro/exvivo characterizations of microemulsion-based hydrogel formulation of aceclofenac for topical application. Asian J Pharm Clin Res 2016;9:87-91.

29. Rawat MSM, Singh D, Semalty A, Semalty M. Emodin-phospholipid complex-A potential of herbal drug in the novel drug delivery system. J Therm Anal Calorim Springer Sci 2012;108:289-98.

30. Pretsch E, Buhlmann P, Badertscher M. Structure determination of organic compounds. Tables of Spectral Data, Springer Sci 2009;4:93-108.

31. Das S, Haldar PK, Pramanik G. Formulation and evaluation of herbal gel containing Clerodendron infortunatum leaves extract. Int J Pharm Tech Res 2011;3:140-3.

32. Kumar TG, Kaur LP. Formulation and evaluation of topical gel of aceclofenac. J Drug Delivery Ther 2013;3:51-3.

33. Sharma S, Kaur IP. Development and evaluation of sesamol as an antiaging agent. Int J Dermatol 2006;45:200-8.

34. Rahman H, Muralidharan P, Anand M. Inhibition of AChE and antioxidant activities are a probable mechanism of Nardostacys jatamansi DC in sleep deprived Alzheimer's mice model. Int J PharmTech Res 2011;3:1807-16.

35. Beutler E, Duron 0, Kelly BM. An improved method for the determination of blood glutathione. J Lab Clin Med 1963;61:882-8.

36. Misra HP, Fridovich I. The oxidation of phenylhydrazine: superoxide and mechanism. Biochemistry 1976;15:681-7.

37. Aebi H. Methods of enzymatic analysis. ed. New York, Academic Press; $1974 ; 2: 674$

38. Ohkawa H, Ohisi N, Yagi K. Assay for lipid peroxides in animal tissues by thiobarbituric acid reaction. Anal Biochem 1979;95:351-8.

39. Li Y, Wu H, Jia M, Cui F, Lin J, Yang X, et al. Therapeutic effect of folate-targeted and PEGylated phytosomes loaded with a mitomycin c-soybean phosphatidylcholine complex. Mol Pharm 2014;11:3017-26.

40. Mukherjee P, Maiti K, Mukherjee K, Gantait A, Saha B. Curcumin-phospholipid complex: preparation, therapeutic evaluation and pharmacokinetic study in rats. Int J Pharm 2007;330:155-63.

41. Skoog D, West D. Principles of instrumental analysis saunders golden sunburst series. $2^{\text {nd }}$ ed; 1992. p. 221-54.

42. Pavia D, Lampman G, Kriz G, Vyvyan J. Introduction to spectroscopy. $4^{\text {th }}$ ed; 1996. p. $142-60$

\section{How to cite this article}

- Parul A Ittadwar, Prashant K Puranik. Novel umbelliferone phytosomes: development and optimization using experimental design approach and evaluation of photo-protective and antioxidant activity. Int J Pharm Pharm Sci 2017;9(1):218-228. 